\title{
JEAN-JACQUes ThOMAS, Perec en Amérique
}

\section{Margareth Amatulli}

\section{(2) OpenEdition \\ Journals}

\section{Edizione digitale}

URL: https://journals.openedition.org/studifrancesi/45438

DOI: $10.4000 /$ studifrancesi.45438

ISSN: 2421-5856

\section{Editore}

Rosenberg \& Sellier

\section{Edizione cartacea}

Data di pubblicazione: 1 août 2021

Paginazione: 399-400

ISSN: 0039-2944

\section{Notizia bibliografica digitale}

Margareth Amatulli, «Jean-Jacaues Thomas, Perec en Amérique», Studi Francesi [Online], 194 (LXV | II) | 2021, online dal 01 septembre 2021, consultato il 15 octobre 2022. URL: http://

journals.openedition.org/studifrancesi/45438 ; DOI: https://doi.org/10.4000/studifrancesi.45438

Questo documento è stato generato automaticamente il 15 octobre 2022.

\section{(c) (i) ()}

Creative Commons - Attribuzione - Non commerciale - Non opere derivate 4.0 Internazionale - CC BYNC-ND 4.0

https://creativecommons.org/licenses/by-nc-nd/4.0/ 


\title{
JeAn-Jacques Thomas, Perec en Amérique
}

\author{
Margareth Amatulli
}

\section{NOTIZIA}

JEAN-JACQUes Thomas, Perec en Amérique, Paris, Les Impressions Nouvelles, 2020, 173 pp.

1 Come recita la quarta di copertina, questo saggio colma un'importante lacuna nella conoscenza bio-bibliografica di Georges Perec rintracciando l'influenza del mondo statunitense sull'opera dello scrittore francese, influenza spesso ridotta al film Ellis Island ma già ravvisabile nelle indagini di mercato di stampo americano raccontate in Les choses. Grazie a un intenso lavoro di archivio, al ricorso a fonti inedite e attraverso un approccio essenzialmente biografico e socio-culturale, lo studio, che ha occupato l'autore per ben cinque anni, si pone l'obiettivo di ricontestualizzare Perec e la sua opera nel panorama intellettuale francese alla luce della partecipazione dello scrittore al mondo intellettuale americano.

2 Dopo aver introdotto le tematiche e le modalità di composizione della singolare scrittura perecchiana, Thomas ripercorre le perec/grinazioni americane e canadesi dell'autore attraverso la cronaca dettagliata dei cinque viaggi negli Stati Uniti e in Canada da lui compiuti per ragioni sia professionali sia affettive tra il 1967 e il 1980. Grazie alla profonda conoscenza del mondo editoriale e universitario americano, lo studioso ricostruisce l'insuccesso della carriera letteraria americana di Perec a partire dalla fredda accoglienza di una cultura che si vedeva in qualche modo criticata dalla propensione ai consumi di Jérôme e Sylvie ad opera di un autore qualificato come non moderno e non in grado di catturare l'interesse di quella classe di «young urban sophisticate» (p. 116) verso cui mirava allora il mercato editoriale statunitense. L'assenza di Perec da quel paesaggio mediatico è anche attribuita ad altri fenomeni quali la sua marginalità rispetto al Nouveau Roman, molto in voga oltreoceano, e al mancato riconoscimento del mondo accademico. Né le difficoltà traduttive dei testi à 
contrainte né la scrittura neutra, poco drammatica, e come tale estranea alla sensibilità anglosassone, hanno favorito la ricezione dell'opera. Paradossalmente, però, Perec trova nell'America un serbatoio di energia intellettuale e vitale per i suoi rapporti interpersonali e per la sua creatività. Configurandosi come una vera e propria eterotopia, tale «espace concret qui héberge l'imaginaire» (Foucault, cit. a p. 153) avrebbe, secondo Thomas, segnato la retorica delle immagini perecchiane attraverso l'influenza del cinema americano e un'estetica visiva più legata alla tecnica del jump-cut che al fermo immagine barthesiano. Merito dello studio è proprio il notevole sforzo di contestualizzazione socio-culturale che coinvolge non solo lo scrittore francese ma il mondo dell'editoria americana ricostruito nelle sue prassi ed esigenze. 